\title{
Ocorrência do vírus da imunodeficiência felina e do vírus da leucemia felina em gatos domésticos mantidos em abrigos no município de Belo Horizonte
}

[Occurrence of feline immunodeficiency virus and feline leukemia virus in Sheltered domestic cats of Belo Horizonte]

\author{
B.M. Teixeira, D.S. Rajão, J.P.A. Haddad, R.C. Leite, J.K.P. Reis* \\ Escola de Veterinária - UFMG \\ Caixa Postal 567 \\ 30123-970 - Belo Horizonte, MG
}

\begin{abstract}
RESUMO
Investigou-se a ocorrência da infecção pelo vírus da imunodeficiência felina (FIV) e pelo vírus da leucemia felina (FeLV) em gatos domésticos, provenientes de dois abrigos, no município de Belo Horizonte. Amostras de sangue de 145 animais foram coletadas e testadas para detecção do FIV pela reação em cadeia da polimerase (PCR). Destas amostras, 40 foram testadas para o antígeno p26 de FeLV por meio de ELISA. Observaram-se duas fêmeas $(1,4 \%)$ e quatro machos $(2,8 \%)$ positivos para FIV e nove fêmeas $(22,5 \%)$ e quatro machos $(10,0 \%)$ positivos para FeLV.
\end{abstract}

Palavras-chave: gato, vírus da imunodeficiência felina, vírus da leucemia felina, PCR, ELISA

\section{ABSTRACT}

The occurrence of the feline immunodeficiency virus (FIV) and feline leukemia virus (FeLV) was investigated in domestic cats from two shelters of Belo Horizonte. Samples from 145 cats were collected and tested for FIV by the polymerase chain reaction (PCR). Forty out of 145 samples were tested for FeLV p27 antigen by a commercial ELISA kit. Two females (1.4\%) and four males (2.8\%) were positive for FIV. For FeLV tests, 13 cats (32.5\%) were positive, being nine females $(22.5 \%)$ and four males $(10.0 \%)$.

Keywords: cat, feline immunodeficiency virus, feline leukemia virus, PCR, ELISA

\section{INTRODUÇÃO}

O vírus da imunodeficiência felina (FIV) e o vírus da leucemia felina (FeLV) pertencem à família Retroviridae e acometem gatos domésticos em todo o mundo (Lutz, 1990).

FIV é um Lentivírus cuja forma predominante de transmissão é a saliva. A transmissão intrauterina, perinatal, pelo leite ou pelo sêmen de machos soropositivos também pode ocorrer (Jordan et al., 1995; O'Neil et al., 1995). Uma vez infectado, o animal pode desenvolver desordens hematológicas e deficiência imunológica, tornando-se susceptível a infecções secundárias (Yamamoto et al., 1989). Como na infecção por HIV, a alteração mais característica é a deleção de linfócitos TCD4 + (Bendinelli et al., 1995).

As taxas mais altas de infecção têm sido encontradas em gatos machos adultos com livre acesso às ruas, os quais, freqüentemente, apresentam comportamento agressivo (Lutz, 1990). Outro fator importante é a condição de saúde do animal (Souza et al., 2002).

FeLV é um Gammaretrovírus transmitido principalmente pelo contato direto freqüente ou prolongado entre animais e pela ingestão de água

Recebido em 22 de maio de 2006

Aceito em 6 de março de 2007

*Autor para correspondência (corresponding author)

E-mail: jenner@coltec.ufmg.br 


\section{Teixeira et al.}

e comida contaminadas (Hoover; Mullins, 1991). $\mathrm{O}$ vírus também pode ser transmitido pelas secreções respiratórias, lacrimais, pelo leite, urina e fezes (Arjona et al., 2000), além de ser possível a transmissão venérea e durante a gestação (Harbour et al., 2002). Os sintomas da infecção incluem leucemias, linfossarcomas, síndromes mieloproliferativas e imunossupressão. Gatos jovens, que vivem em grupos com contato íntimo entre os animais são mais susceptíveis à infecção (Hoover; Mullins, 1991).

O diagnóstico das infecções por FIV e FeLV é feito pela associação do exame clínico, geralmente inconclusivo, com exames laboratoriais complementares. Os testes sorológicos para detecção de anticorpos específicos ou antígenos virais são muito utilizados, como o ensaio de imunoadsorção enzimática -ELISA (Miyazawa, 2002). Além disso, testes moleculares, como a reação em cadeia da polimerase (PCR), são eficientes para a detecção do DNA proviral (Caldas et al., 2000; Miyazawa, 2002).

A infecção por FIV e por FeLV ocorre em gatos domésticos de todo o mundo, com prevalências que variam de $1 \%$ a $44 \%$ e de $1 \%$ a $38 \%$, respectivamente (Hosie et al., 1989; Ishida et al., 1989; Braley, 1994). No Brasil, já foi detectada por meio de pesquisas sorológicas e pela PCR, em gatos domésticos domiciliares e de rua, nos estados de São Paulo, Rio de Janeiro, Rio Grande do Sul e Minas Gerais, com prevalências que variam de menos de $2,0 \%$ a $37,5 \%$ e de $8,0 \%$ a $63,0 \%$ para FIV e FeLV, respectivamente (Caldas et al., 2000; Souza et al., 2002; Caxito, 2003; Almeida et al., 2004), e a ocorrência do FIV subtipo B em Minas Gerais foi comprovada por meio de estudo filogenético, realizado por Caxito et al. (2006).

O objetivo deste trabalho foi verificar a ocorrência da infecção por FIV e FeLV em gatos domésticos de abrigos em Belo Horizonte, MG.

\section{MATERIAL E MÉTODOS}

Foram coletadas 145 amostras de sangue, por meio de punção venosa, de gatos domésticos capturados nas ruas de Belo Horizonte e que se encontravam em dois abrigos, sendo 80 animais da Sociedade Protetora dos Animais e 65 de um abrigo em Ribeirão das Neves.

As amostras foram coletadas em dois tubos, um contendo anticoagulante EDTA para obtenção de células mononucleares do sangue periférico (PBMC) e outro sem anticoagulante para obtenção de soro. As células mononucleares foram obtidas pelo método Ficoll-Hypaque ${ }^{1}{ }^{1}$ de acordo com as recomendações do fabricante. O DNA foi extraído, seguindo-se protocolo utilizado por Hohdatsu et al. (1992). Após a extração, a quantidade de DNA obtida foi estimada por espectrofotometria e mantida a $20^{\circ} \mathrm{C}$ até a realização dos testes.

A PCR foi realizada utilizando-se iniciadores para amplificação de um fragmento de 244 pares de bases do gene gag do FIV de acordo com a técnica empregada por Hohdatsu et al. (1992), cujas seqüências são 5, CTAGGAGGTGAGGAAGTTCA 3' (Senso) e 5' CTGCTTGTTGTTCTTGAGTT 3' (Antisenso).

As reações foram realizadas em um volume total de $20 \mu \mathrm{l}$ contendo: $10 \mathrm{mM}$ de TrisHCl $\mathrm{pH} 8,3$; $50 \mathrm{mM}$ de $\mathrm{KCl} ; 1,5 \mathrm{mMde} \mathrm{MgCl}_{2}, 1 \%$ de glicerol $(\mathrm{p} / \mathrm{v}) ; 1 \%$ de DMSO (p/v); 10 pmoles de cada iniciador; $0,2 \mathrm{mM}$ de cada deoxinucleotídeo ${ }^{2}$; $0,5 \mathrm{U}$ de Taq DNA polimerase ${ }^{3}$ e $2 \mu 1$ do DNA molde. Uma fina camada de óleo mineral foi adicionada a cada microtubo. A reação de amplificação foi realizada em um termociclador programável $^{4}$.

Os ciclos padronizados para amplificação do DNA foram realizados conforme descritos por Hohdatsu et al. (1992): uma incubação inicial a $94^{\circ} \mathrm{C}$ por 5 minutos, seguida de 35 ciclos, cada um consistindo de desnaturação a $94^{\circ} \mathrm{C}$ por 60 segundos, hibridização a $55^{\circ} \mathrm{C}$ por 120 segundos, extensão pela polimerase a $72^{\circ} \mathrm{C}$ por 120 segundos e extensão final a $72^{\circ} \mathrm{C}$ por 5 minutos.

Após a PCR, duas amostras de fragmentos amplificados foram submetidas ao seqüenciamento de nucleotídeos por ciclagem térmica em seqüenciador automático ${ }^{5}$. A seqüência editada foi, então, analisada para a

\footnotetext{
${ }^{1}$ Amersham Pharmacia Biotech - Piscataway, EUA

${ }^{2}$ Promega - Madison, EUA

${ }^{3}$ Gibco-BRL Invitrogen - Carlsbad, EUA
} 
determinação de homologia com seqüências de FIV depositadas no banco de genomas, GenBank $^{6}$.

Das 145 amostras coletadas, 40 foram separadas aleatoriamente e submetidas a um ELISA, utilizando-se $\mathrm{kit}^{7}$, com capacidade de detectar a proteína p27 de FeLV.

\section{RESULTADOS}

Dos 145 animais analisados pela PCR, seis $(4,14 \%)$ apresentaram resultado positivo para FIV, sendo quatro machos e duas fêmeas (Tab. 1).

Tabela 1. Ocorrência do vírus da imunodeficiência felina em gatos, capturados em Belo Horizonte e mantidos em abrigos, testados pela PCR

\begin{tabular}{ccc}
\hline Sexo & $\mathrm{N}^{\text {o de animais }}$ & Positivos \\
\hline Macho & $57(39,31 \%)$ & $4(2,76 \%)$ \\
Fêmea & $88(60,69 \%)$ & $2(1,38 \%)$ \\
\hline Total & $145(100 \%)$ & $6(4,14 \%)$ \\
\hline
\end{tabular}

Das 40 amostras de soro analisadas por meio do ELISA, $13(32,5 \%)$ apresentaram resultado positivo para o FeLV (Tab. 2).

Tabela 2. Ocorrência de resultados positivos para FeLV encontrados pelo ELISA em gatos capturados na rua e mantidos em abrigos em Belo Horizonte

\begin{tabular}{ccc}
\hline Sexo & $\mathrm{N}^{\circ}$ de animais & FeLV \\
\hline Macho & $13(32,5 \%)$ & $4(10,0 \%)$ \\
Fêmea & $27(67,5 \%)$ & $9(22,5 \%)$ \\
\hline Total & $40(100 \%)$ & $13(32,5 \%)$ \\
\hline
\end{tabular}

\section{DISCUSSÃO}

Apesar da população de felinos, utilizada neste trabalho, constituir-se de animais provenientes da rua, com condições nutricionais ruins e ausência do controle de infecções, os valores de ocorrência de FIV são inferiores aos encontrados em outros estados. A detecção do vírus pela PCR foi relatada em São Paulo (13,4\%), Rio Grande do $\operatorname{Sul}(37,5 \%)$ e em Minas Gerais (2,7\%), com taxas de ocorrência variando de acordo com a região (Caldas et al., 2000; Caxito, 2003). Estudos sorológicos detectaram a ocorrência de anticorpos contra o FIV em São Paulo (11,7\%) e no Rio de Janeiro ( $16,7 \%$ e $21,0 \%$ ), porém o método sorológico pode gerar resultados falsopositivos, levando a uma taxa de ocorrência maior que a real (Reche Jr. et al., 1997; Souza et al., 2002; Almeida et al., 2004).

${ }^{4}$ MJ Research, Inc. Globalspec - Waltham, EUA

${ }^{5}$ ALF - Amersham Pharmacia Biotech - Uppsalla, Suécia

${ }^{6}$ National Center for Biotechnological information Bethesda, EUA

${ }^{7}$ Snap combo felino da IDEXX® ${ }^{\circledR}$ - Westbrook, EUA.
Em estudo anterior realizado em Minas Gerais (Caxito, 2003), foram encontrados resultados diferentes para gatos que viviam em ambiente doméstico $(3,0 \%)$ e de rua $(1,1 \%)$. O resultado encontrado para os animais de rua foi inferior ao encontrado neste estudo, apesar de também ter sido utilizada a PCR.

Comparando-se as seqüências das duas amostras obtidas com as seqüências de amostras japonesas (número de acesso 37823 e 37824 ) descritas por Kakinuma et al. (1995), foi encontrado de 96 a $98 \%$ de homologia entre nucleotídeos, mostrando alto grau de conservação dessa região do gene gag de amostras brasileiras com amostras japonesas do FIV.

O ELISA detectou $13(32,5 \%)$ de amostras positivas para FeLV, este resultado foi superior aos encontrados em estudos realizados em outros estados do Brasil. Reche Jr. Et al. (1997) e Souza et al. (2002) observaram $8 \%$ e $17 \%$ de animais positivos, respectivamente, nos estados de São Paulo e Rio de Janeiro. A ocorrência encontrada é inferior à observada em estudo anterior realizado em Minas Gerais (Coelho, 2003), que detectou pela Nested-PCR uma ocorrência de 63,36\%. A discrepância entre os resultados anteriores e os do presente trabalho pode estar relacionada à diferença de métodos de diagnóstico utilizados.

A alta ocorrência da infecção pelo FeLV pode estar também influenciada pela caracterização das populações analisadas, que compreendiam animais vivendo em ambientes com alta densidade populacional, mantendo íntimo e 


\section{Teixeira et al.}

freqüente contato entre eles. Estudos anteriores demonstraram tal influência, observando a maior incidência da infecção em criadouros com mais de seis gatos (Braley, 1994).

Apesar de gatos machos serem apontados como os mais afetados pela infecção por FIV e FeLV (Hosie et al., 1989; Braley, 1994), o número de animais testados não foi suficiente para observar variações entre os sexos.

Os resultados sugerem que a procedência dos animais, neste caso, de rua, pode ser fator importante para a transmissão de FIV.

Neste trabalho, demonstrou-se a ocorrência dos vírus da imunodeficiência felina e da leucemia felina em gatos de rua que vivem em abrigos de Belo Horizonte, Minas Gerais.

\section{REFERÊNCIAS BIBLIOGRÁFICAS}

ALMEIDA, F.M; FARIA, M.C.F; BRANCO, A.S et al. Sanitary conditions of colony of urban feral cats (Felis catus Linnaeus, 1758) in a Zoological Garden of Rio de Janeiro, Brazil. Rev. Inst. Med. Trop. São Paulo, v.46, p.269-274, 2004.

ARJONA, A.; ESCOLAR, E.; SOTO, I. et al Seroepidemiological survey of infection by feline leukemia virus and immunodeficiency virus in Madrid and correlation with some clinical aspects. J. Clin. Microbiol., v.38, p.34483449, 2000.

BENDINELLI, M.; PISTELLO, M.; LOMBARDI, S. et al. Feline immunodeficiency virus: an interesting model for AIDS studies and an important cat pathogen. Clin. Microbiol. Rev., v.8, p.87-112, 1995.

BRALEY, J. FeLV and FIV: survey shows prevalence in the United States and Europe. Feline Pract., v.22, p.25-28, 1994.

CALDAS, A.P.F.; LEAL, E.S.; SILVA, E.F.A. et al. Detecção do provírus da Imunodeficiência Felina em gatos domésticos pela técnica de reação em cadeia da polimerase. Pesq. Vet. Bras., v.20, p.20-25, 2000.

CAXITO, F.A. Detecção e subtipagem do vírus da imunodeficiência felina em Minas Gerais. 2003. 90f. Dissertação (Mestrado) - Instituto de Ciências Biológicas, Universidade Federal de Minas Gerais, Belo Horizonte.

CAXITO, F.A.; COELHO, F.M.; OLIVEIRA, M.E. et al. Phylogenetic analysis of feline immunodeficiency strains from State of Minas Gerais, Brazil. Arq. Bras. Med. Vet. Zootec., v.58, p. 1222-1225, 2006

COELHO, F.M. Ocorrência do DNA proviral do vírus da leucemia felina em Felis catus detectado por Nested - PCR.
2003. 99f. Dissertação (Mestrado) - Instituto de Ciências Biológicas, Universidade Federal de Minas Gerais, Belo Horizonte.

HARBOUR, D.A.; GUNN-MOORE, D.A.; GRUFFYDDJONES, T.J. et al. Protection against oronasal challenge with virulent feline leukaemia virus lasts for at least 12 months following a primary course of immunisation with Leukocell $^{\mathrm{TM}} 2$ vaccine. Vaccine, v.20, p.2866-2872, 2002.

HOHDATSU, T.; YAMADA, M.; OKADA, M. et al. Detection of feline immunodeficiency proviral DNA in peripheral blood lymphocytes by the polymerase chain reaction. Vet. Microbiol., v.30, p.113-123, 1992.

HOOVER, E.A.; MULLINS, J.I. Feline leukemia virus infection and diseases. J. Am. Vet. Med. Assoc., v.199, p.1287-1297, 1991

HOSIE, M.J.; ROBERTSON, C.; JARRET, O. Prevalence of feline leukaemia virus and antibodies to feline immunodeficiency virus in cats in United Kingdom. Vet. Rec., v.128, p.293-297, 1989.

ISHIDA, T.; WASHIZU, T.; TORIYABE, K. et al. Feline immunodeficiency virus infection in cats of Japan. J. Am. Vet. Med. Assoc., v.194, p.221-225, 1989.

JORDAN, H.L.; HOWARD, J.; TOMPKINS, W.A. et al. Detection of feline immunodeficiency virus in semen from seropositive domestic cats (Felis catus). J. Virol., v.69, p.7328-7333, 1995.

KAKINUMA, S.; MOTOKAWA, K.; HOHDATSU, T. et al. Nucleotide sequence of feline immunodeficiency virus: classification of Japanese isolates into two subtypes which are distinct from non-Japanese subtypes. J. Virol., v.69, p.3639-3646, 1995.

LUTZ, H. Feline retroviruses: a brief review. Vet. Microbiol. v.23, p.131-146, 1990.

MIYAZAWA, T. Infections of feline leukaemia virus and feline immunodeficiency virus. Front. Biosci., v.7, p.504$518,2002$.

O'NEIL, L.L.; BURKHARD, M.J.; DIEHL, L.J. et al. Vertical transmission of feline immunodeficiency virus. AIDS Res. Hum. Retrovirus, v.10, p.267-278, 1995.

RECHE JR., A.; HAGIWARA, M.K.; LUCAS, S.R.R. Clinical study of acquired immunodeficiency syndrome in domestic cats in São Paulo. Braz. J. Vet. Res. Anim. Sci., v.34, p.152-155, 1997.

SOUZA, H.J.M.; TEIXEIRA, C.H.R.; GRAÇA, R.F.S. Estudo epidemiológico de infecções pelo vírus da leucemia e/ou imunodeficiência felina, em gatos domésticos do município do Rio de Janeiro. Clin. Vet., v.36, p.14-21, 2002.

YAMAMOTO, J.K.; HANSEN, H.; HO, E.W. et al. Epidemiologic and clinical aspects of feline immunodeficiency virus infection in cats from the continental United States and Canada and possible mode of transmission. J. Am. Vet. Med. Assoc., v.194, p.213-220, 1989. 